\title{
THE CHEVALIER TAYLOR AND HIS STRABISMUS OPERATION*†
}

\author{
BY \\ FREDRIK BERG \\ Uppsala, Sweden
}

IN several of his many writings Taylor maintained that he could cure squint without risk by a prompt and almost painless operation. As far as has been known up to now, he himself never described the theoretical basis and the method of his operation. We have had information only from his contemporaries, who described his mode of procedure. At Rouen, Lecat (1743) saw him cutting off a strip of conjunctiva, pretending to cure a strabismus. In 1750 at Rostock, Eschenbach (1752) heard a lecture by Taylor who said that he could cut through one of the rectus muscles, and in 1751 at Copenhagen, Heuermann (1756) understood that his method was to cut through the tendon of the superior oblique. Neither at Rostock nor at Copenhagen did Taylor actually perform the operation.

The question of Taylor's operation has been thoroughly discussed by many medical historians, including Antonelli (1902), Hirschberg (1912), and Coats (1915). The general assumption seems to support the opinion of Coats, who summarizes as follows:

On the whole the impression conveyed is that he recognized clearly that squint was a disturbance of muscle equilibrium; that he conceived the idea that it might be cured by dividing a muscleand in this conception apparently he is really entitled to the credit of priority; that either with, or very much more probably without, having made the attempt, he became convinced that the operation was impracticable; that in order not to lose his dishonest emoluments he devised the fraudulent procedure described by Lecat; that for the hoodwinking of intelligent onlookers or critics he further invented two stories-first, that he divided a nervous filament; second, that his stitch served to fix the globe while he divided the muscle.

Having visited Rostock and Copenhagen, Taylor went to Stockholm where he spent the last four months of the year 1751. There he gave demonstrations of his instruments and operations, and also a series of lectures on the eye and its diseases, as apparently he had done in other places.

In the library of Karolinska Institutet, Stockholm, is preserved an interesting manuscript (Ms. 158:1:11) consisting of annotations made during Taylor's lectures by the prominent Swedish physician Abraham Bäck. On the first leaf there are some very surprising notes on squint. In children the squint is caused by a bad habit and must be treated with a special "machine" of Taylor's own design.

"But in grown-up people who squint since childhood, one ought to cut through a larger

* Received for publication June 13, 1966.

† Address for reprints: Prof. Fredrik Berg, Uppsala, Sweden. 
or smaller part of the aponeurosis musculi recti interni, which often helps but never makes it worse, yet sometimes fails because of different number and position of the muscles."

Bäck's notes give, however, no hints about Taylor's own theory on strabismus, nor is any actual operation mentioned. It seemed to me rather remarkable that these lectures in Stockholm, and probably in Rostock and Copenhagen, should be the only occasions on which Taylor had revealed his method of squint operation.

One of Taylor's books, "The History of the Travels, etc." (Taylor, 5, I, p. 22), contains a list of his own publications, among others (No. 38) "A dissertation on the art of restoring the healthful position of the eye, lost by a vice known by the name of strabismus, with many figures; addressed to the royal infant duke of Parma. Italian. 4to. Milan, 1756." This title is also included in the comprehensive bibliography of Coats (No. 19) with the addition: "No copy known". Antonelli mentioned that he had tried to find the book in libraries at Milan, but in vain. My friend Dr. $H$. Sallander at the University library, Uppsala, advised me to inquire for the book at the Biblioteca Palatina di Parma. It was a pleasant surprise to receive the answer that the Dissertation was in the library's possession, and I very soon obtained a xerocopy. The full title of the Dissertation is given in the References (Taylor, 4). Besides some pages with dedication, etc., the booklet contains 28 pages of text, followed by six pages of index, a list of the author's earlier publications (amounting to thirty), and an announcement of four papers to be printed in the near future. There are also some figures (missing in the copy).

In this Dissertation Taylor gives a comprehensive account of his idea of squint and of the theoretical background of his operation. As an introduction he says that he wishes to call attention to this disease, till then regarded as incurable, having no other purpose than to inform the public about a method to heal a defect which so strikingly ruins the beauty of a person and of an eye. According to his definition, strabismus is an unnatural position of one or both eyes, in which the axis of one eye corresponds to a line perpendicular to the centre of the orbit, and the axis of the other is more or less deviating.

A survey follows of ancient and modern opinions on the nature of strabismus. In antiquity there was a vague conception of a defect of one or other muscle. At the beginning of the 18th century different theories were brought forward. Some authors were of the opinion that strabismus was caused by an oblique position of the lens (Ferrein, 1733). Some thought there was an abnormal convexity of the cornea (Maître-Jean, 1707). Others found the cause in a displacement of the most sensitive part of the retina (Porterfield, 1737). Taylor gives a fairly extensive account of these opinions and refutes the three last on more or less convincing grounds, the most conclusive being the immediate adjustment of the squinting eye as soon as the fixing eye is covered. Most of the arguments are to be found also in Taylor's earlier publications (especially Taylor, 1, p. 178, and Taylor 2, p. 173). In the dissertation he also mentions Saint-Yves but in a contemptuous tone, saying that Saint-Yves expresses himself so badly and with such irregularity that Taylor wishes to spare the reader a detailed account of his book. In earlier papers Taylor does not mention Saint-Yves, and his judgment of him is the more noteworthy as the theory of SaintYves was till then the best founded and undoubtedly very near Taylor's own, which can be said to be merely complementary to that of Saint-Yves. 
According to Saint-Yves (1722), strabismus in children is a discordance in motion of one of the rectus muscles. When the defect occurs in grown-up people it is usually caused by a paralysis of an eye muscle. In this case diplopia (or even triplopia) arises, because the rays strike different fibres in the eyes and thus give rise to more than one sensation in the "sensus communis". The conception of corresponding areas of the retina is clearly expressed by Saint-Yves, and also that the difference between concomitant and paralytic strabismus consists in the free mobility of the squinting eye in the former, and the diplopia in the latter. The ideas of Saint-Yves are repeated by Taylor, but he gives no hint of having adopted them from SaintYves.

Taylor classifies strabismus into four groups:

(1) When the axis of only one eye is more or less diverted towards the angulus major (canthus medialis), the axis of the other being directed in a right line towards the centre of the orbita (strab. concom. conv. unilateralis).

(2) When the axes of both eyes are more or less directed towards the angulus major (from the subsequent reasonings it is evident that he means strab. conv. alternans).

(3) When the axis of only one eye is more or less diverted towards the angulus minor (canthus lateralis), the axis of the other being in right line with the orbita (strab. conc. diverg. unilateralis).

(4) When the axis of only one eye is more or less diverted upwards towards the most distant part of the orbita (strab. sursum vergens).

The same classification is used in Taylor's "Kurze Anleitung, etc." (Taylor, 3). It is to be observed that in this book Taylor also gives a list of those diseases which may be cured only by operation (p. 109) and among them (No. 25) strabismus of the first kind. In earlier works (e.g. Taylor, 1, p. 284) only the first three groups are included. In "The History of the Travels, etc." (Taylor, 5, I, p. 31), there is a list of the lectures he used to give, and Praelectio VIII has the following contents:

"In this lecture the author treats on the muscles of the globe-and of that defect, known by the name of strabismus - shews that there are four species of this disorder; and demonstrates, by a theory entirely new, that one of these species at least may be cured; and that it is not impossible, from the same theory, but a remedy may be found for the cure of every other."

In the dissertation, dealing with the infant squint, Taylor repeats the usually supposed causes, such as imitation, looking at objects placed askew, etc., which may bring about a disturbance of the natural equilibrium of the muscles. However, as the squinting eye has its normal mobility when the other eye is covered, he concludes that the disturbance of the equilibrium is valid, not between the muscles of one eye, but between the muscles of one eye and those of the other. He also states that the distance between the two pupils is always the same in all directions of looking, except when the object is brought very near the eyes. However, as the action of the muscles is entirely dependent on their nerves, the disturbance of the equilibrium must have its seat in the muscular nerves. To this extent, Taylor's conclusions are more advanced than those of Saint-Yves.

Regarding the absence of diplopia in squint, Taylor explains that the image produced by rays going obliquely to the axis of the eye is very confused and thus easily suppressed, and also that an object situated along the axis of a squinting eye 
does not bring about a sensation because our sensus communis is not able to actualize more than one thing at the same time. The fact that diplopia arises upon pressing one eye by a finger, Taylor explains in referring to the small deviation of the axis, not bringing the image outside the most sensitive part of the visual organ.

To treat squint in children, Taylor had invented a special instrument or mask with movable holes to correct the deviation gradually. The idea was apparently derived from Saint-Yves. Details are here omitted. The operation was not to be used on children.

The most interesting part of the dissertation deals with the theoretical background of Taylor's operation. As the defect depends on the nerves supplying the muscles, the idea struck Taylor that if it were possible to cut off one or some of the former, it would be possible to weaken the muscle and give the antagonist the opportunity to restore the normal position of the eye. For this purpose he had dissected all the nerves entering the muscles, and refers to his "Trattato Anatomico" (apparently "Le mechanisme, etc.", Taylor, 1). In this book the anatomical description is correct, except for some errors or possibly misprints, and corresponds closely to the handbook of Winslow (1732). The second branch of the third nerve goes to the medial rectus muscle. The first branch of the fifth nerve has anastomoses with the sixth and the nervus intercostalis (sympathetic) and divides into three branches. The second of these runs forwards between the medial rectus and superior oblique muscles right on to the angulus major and disappears in the caruncula and lacrimal sac. During its course it sends a filament to the ciliary ganglion.

"One observes that this branch sends on all sides several filaments to the muscles where it passes and runs as far as to the nervi olfactorii" (p. 54).

Apparently Taylor has the infratrochlear nerve in mind, and one of the muscles passed by this is the medial rectus.

The dissertation continues with the following statement, quoted in close translation:

"The branches of the sixth pair together with nervus orbitalis and some filaments from intercostalis as well as only the second branch of the third pair (the first of these goes to the rectus externus and the second to the rectus internus) are both different in regard to number and situation like other smaller nerves; but those to rectus internus pass to the outer part of the muscle, while those to externus disappear in several parts of the belly of the muscle. From this explanation of the small branches to these muscles it is evident that the nerves of internus may be severed and consequently the force of the muscle be reduced; on the contrary, it is impossible to sever the nerves of externus without destroying the muscle itself; from which follows that no method can with reason be tried to restore the muscles unless in those species of squint when the pupil is deviated inwards.

The reason that has caused me to make this investigation is that I have accidentally injured one or some of these nerves wishing to excise a part of the conjunctiva in a violent inflammation, and, that being done, both eyes had regained their normal position which had been lost for many years.

This lucky event has given me courage to try the cure of squint by cutting through (tagliando attraverso) a more or less considerable part of the aponeurosis musculi recti interni, as I have since then practised on many patients, and many times I have attained the desired success; in those however where the success has failed, the eye has remained in the same position, but never worse, and this without exposing the patient to any noteworthy 
pain. The reason why such an operation sometimes is without success is to be attributed to the number and accidental situation of the nerves of the muscles."

A few comments to this text may be added.

Regarding the infratrochlear nerve, Winslow says in his "Anatomy" (III, p. 149) that this nerve passes above the medial rectus muscle and reaches the internal canthus, where it gives branches to the adjacent parts, namely the caruncle, the lacrimal sac, the adjacent parts of the orbicularis, the superciliaris and the pyramidalis muscles, as well as to the integument. As the nerve, according to Winslow, contains motor fibres, it might have seemed probable to Taylor that there could be some motor fibres also to the medial rectus. And in his dissection he possibly found some filaments to the nasal part of the conjunctiva, covering the most distal part and the tendon of the medial rectus, which fibres he attributed-not quite disinterestedly - to the muscle.

Taylor's history of the accidental cutting of the nerves in excising a strip of conjunctiva must imply, if it is true, that the cutting was rather deep.

The well-known event at Rouen, described by Lecat (1743) (quoted by Antonelli and referred to by Coats), when Taylor in that year in the presence of Lecat performed an operation, is worthy of being quoted:

With a needle provided with a thread of silk he took a portion of the conjunctiva of the eye near the inferior part of the globe, and having made a loop of the silk thread, he used it for attracting the portion of conjunctiva which was included and then cut it off with scissors; at last he put a plaster on the sound eye, the squinting eye turned right and everyone cried miracle! ... I took again the liberty which he had granted me, asking him for the motive of an operation which seemed to me completely useless, not to say dangerous. He answered me that an eye squinted only because the equilibrium between its muscles was destroyed, and to restore the equilibrium it was only a question of weakening the muscle which had got predominance over the others, and that was what he did in cutting off the nerve-fibres going to this over-strong muscle.

I responded that I didn't know any nerve fibre which did go to the muscles of the eye from the portion he had incised. He retorted that he would show it to me on the first eye I would procure, and I accepted his proposal.

Then Lecat describes how he dissected with exactness all the nerves in question on a human head and how he presented it dramatically to Taylor during a meal as a dessert. According to Lecat, Taylor was stunned and at a loss for a reply. Soon afterwards Taylor left Rouen and "the squinting people, getting rid of the plasters, became again squinting within a couple of days".

Lecat thought that he had unveiled Taylor as a fraudulent charlatan. The description of the operation and Taylor's defence are however in full accord with the theory presented in the dissertation. The operation must therefore be regarded as an honest attempt to cure strabismus, and not as a fraud. This opinion is confirmed by Taylor's reply that he was willing to point out the nerve on the first eye presented to him.

However, the event at Rouen may have given Taylor something to ponder upon. Some years later, at Rostock, Copenhagen, and Stockholm, he seems to have talked only of severing a muscle or an aponeurosis. Eschenbach (1752) says that one or the other oculist (meaning Taylor) dreams of cutting through, completely or partly, 
the muscle mainly at fault. Such a thing can, however, according to Eschenbach, be suggested only by somebody who is not acquainted with surgery. And Heuermann (1756) tells us that Taylor had pretended to cure strabismus by severing the tendon of the superior oblique. This must be a mistake by Heuermann. Taylor probably said the same in Copenhagen as in Rostock and Stockholm. Heuermann was a German by origin and might have had difficulty in understanding Taylor's English. Finally, Bäck in Stockholm quotes Taylor in accordance with the dissertation, also stating that the operation is applicable only in grown-up people. Yet, it may be observed that Bäck speaks of irregularities of the insertion of the muscle, and Taylor in the dissertation of irregularities of the nerves.

Has Taylor corrected his theory and does he now intend to weaken the muscle by cutting off the tendon instead of the nerves? The dissertation was published 5 years after the visit to Sweden, and he still maintains that the operation is possible only on the medial rectus muscle and not on the lateral because the nerves of the latter are inaccessible. It seems more likely that he had come to the conclusion that it was necessary to cut through a larger or smaller part of the tendon to reach the nerves. $\mathrm{He}$ also points to irregularities of the innervation as a cause of failure. Perhaps he thought the unsuccessful attempt at Rouen was caused by an anomaly of the nerves? Or was it a pretence on his part, not wishing publicly to alter his old theory about the nerves?

After all, both in the notes of Bäck and in the dissertation, Taylor's statement of the effect of an operation-often helping, sometimes failing, never injuring-seems to be a weighty reason to believe that he had actually performed some operations for strabismus with success. If all of it were only a cheat, it is difficult to understand why Taylor should admit failure in some cases.

An indication that at least some of the operations were successful lies also in what Taylor says after the quoted lines about the operation. He repeats that there is no diplopia in squint, but that when the eye is returning to its normal position, diplopia appears. During squinting the image of the faulty eye is too diffuse and too peripheral to be observed, but in healing the rays run nearer to the axis of the eye, and then the image of the squinting eye becomes discernible. The cause is that the nerve filaments of both eyes do not correspond from the beginning, but as soon as they correspond, the diplopia disappears.

In addition to concomitant strabismus, the dissertation also deals with squint as a consequence of paralysis, in connexion with congenital cataract, and after injuries of the eye. If it is caused by a nervous disease this must be treated, but if the fault continues into adult life an operation may be possible. Taylor does not pretend to have performed such an operation. In cases of congenital cataract the strabismus usually disappears after a cataract operation, but in adults, there is little hope that the recovery of the sight will improve the position of the eyes. As a sequel of an injury to the muscles the squint is also incurable.

The dissertation ends as follows:

So I conclude my dissertation by declaring that I do not pretend to speak of those irregular changes of the eye which are purely symptomatic, as an epileptic or hysteric disease, etc., but solely of the defect known by the name strabismus or luscitas. 
It remains only to add that, although till now the healing of this disease has not turned out in every case with success, the theory I have laid down of its nature cannot be subject to doubt. I dare even hope that, in the course of time, it will be possible, by means of the given theory, to find a remedy for this disease equally certain as those I have been able to learn and to practise with the most happy effect in many other diseases.

On the whole, the dissertation on strabismus belongs to the best of Taylor's writings. It is comparatively free from boasting pretensions, and the reasoning is logically consistent, irrespective of a fatal anatomical mistake. But had he not tried to cut the nerve, he had probably never dared to cut the tendon of the muscle. The idea was entirely new, and he fulfilled it with boldness and consistency in spite of warnings from contemporary surgeons.

Antonelli, A. (1902). Arch. Ophtal. (Paris), 22, 45.

Coats, G. (1915). Roy. Lond. ophthal. Hosp. Rep., 20, 1. Reprinted by James (1933).

EsCHENBACH, C. E. (1752). "Gegründeter Bericht von dem Erfolg der Operationen des Englischen Oculisten Taylor's, etc.”. Rostock. (Cited by Antonelli, 1902). (1754). "Chirurgie", p. 773. Rostock.

Ferrein, A. (1733). Journal des Sçavans, 100, 458.

HeuermanN, G. (1756). "Abhandlungen der vornehmsten chirurgischen Operationen am menschlichen Koerper”, vol. 2, p. $538 . \quad$ Copenhagen and Leipzig.

HirschberG, J. (1912). "Graefe-Saemisch Handbuch der gesamten Augenheilkunde", 2nd ed., vol. 14, pt 3, p. 289. Engelmann, Leipzig.

JAMES, R. R. (1933). " "Studies in the History of Ophthalmology in England prior to the Year 1800", p. 132. Cambridge.

LecAT, C. N. (1743). “Mémoire pour servir à l'histoire des fourberies des charlatans, etc.”. In "Précis analytique des travaux de l'Académie des Sciences de Rouen”, 1, 110 [1814] (Cited by Antonelli, 1902).

Maître-Jean, A. (1707). "Traité des maladies de l'oeil, etc.”, p. 431. Troyes.

PORTERFIELD W. (1737). "An Essay concerning the Motion of the Eyes", in "Medical Essays and Observations", publ. by a Society in Edinburgh, 4th ed., 1752, vol. III, p. 149.

SAINT-Yves, C. (1722). "Nouveau traité des maladies des yeux etc.", p. 157. Paris.

TAYLOR, J. 1 (1738). "Le mechanisme ou le nouveau traité, etc.", Paris. (Coats, 1915, Ref. No. 4). 2 (1750). " "Mechanismus oder neue Abhandlung, etc.", Frankfurt am Mayn (Coats, No. 4a).

3 (1750). " "Kurze anleitung zu den Vorlesungen etc.", Frankfurt am Mayn (Coats No. 9c).

4 (1756). "Dissertazione/sopra l'arte/Di ristabilire la sana posizione degli Occhi, prodotta da un vizio/conosciuto sotto nome di Strabismo, o sia guardar losco,/con una critica rilevante/Sopra di quelli tanto Antichi, quanto Moderni, che hanno scritto/sopra questa importante materia./Vi si trova una Teorìa del tutto nuova intorno la vera causa di tale difetto;/come pure un Metodo nuovo, non solamente per curare con somma/facilità certe specie contra l'opinione generalmente ricevuta,/ma altresì un modo di preservare li Fanciulli/da questo male,/Ornata con Figure,/umilimente dedicata/a Sua Altezza Reale/il Serenissimo/Don Filippo/Infante di Spagna,/Duca di Parma, Piacenza, Guastalla ec. ec./del Cavaliere Giovanni di Taylor/Medico oculista Pontif. Cesar. Reale ec./di Sua Altezza Reale l'Infante Duca di Parma,/e di S.A.S. il Sig. Duca di Modena ec. ec./In Milano )( MDCCLVI./ Nella R.D.C., per Guiseppe Richino Malatesta Stampatore Reg. Cam."

5 (1761-62). "The History of the Travels and Adventures of the Chevalier John Taylor etc.". London. (Coats No. 19).

WinsLow, J.-B. (1732). "Exposition anatomique de la structure du corps humain", 4 vols. Amsterdam. 